\title{
Análise de políticas sociais para idosos no Brasil: um estudo bibliográfico
} Analysis of Social policies for the elderly in Brazil: a literature review

1 Karin Alves do Amaral Escobar karinseso@gmail.com

2 Flávia Aparecida de Môura

1 Docente do Curso Serviço Social do Centro Universitário de Volta Redona, UniFOA.

2 Discente do Centro Universitário de Volta Redona, UniFOA.

\section{Resumo}

O processo de envelhecimento apresenta reflexões no campo social, econômico, biológico e comportamental, gerando assim um grande desafio para as políticas sociais, a fim de que se melhorem as condições de vida do idoso em diversos aspectos. No Brasil, as discussões em torno do envelhecimento foram influenciadas pelas diretrizes internacionais da Organização Mundial da Saúde e Organização das Nações Unidas que contribuíram para a implementação de políticas específicas voltadas para esse segmento. 0 presente estudo objetiva realizar uma análise das políticas sociais direcionadas aos idosos, identificando os princípios, as orientações, os papéis previstos para a família, comunidade e Estado, assim como identificar a concepção de velhice expressa nesses documentos. 0 presente estudo se caracteriza por pesquisa teórica e bibliográfica que desvenda conceitos, discussões polêmicas e teóricas acerca do assunto estudado. Consideramos que a velhice é um fenômeno histórico, social, cultural, político e psicológico que perpassa as trajetórias de vida pessoal e social e que deve ser compreendida em determinado tempo, espaço, classe social, relações de gênero e de etnia, dentre outras variáveis. Observamos que a criação de políticas específicas de atendimento a esse segmento não retira a centralidade dos cuidados e assistência que ainda recai sobre a família e a comunidade. Constituemse desafios o fortalecimento da participação social, promoção do envelhecimento ativo; estímulo às ações intersetoriais, visando à integralidade da atenção à pessoa que envelhece.

\section{Palavras-chave}

Envelhecimento; políticas sociais; idoso.

\begin{abstract}
The social aging process presents reflexions on the social, economic, biological and behavioral fields, causing a great challenge for social policy, in order to improve the life conditions of the elderly in many aspects. In Brazil, the discussions around aging were influenced by the international guidelines from World Health Organization and United Nations Organization which contributed for the implementation of the policies specific for this segment. This study aims to analyze the social policies destined for the elder, identifying the principles, guidelines, family and State roles, as well as identify the concept of eld. The present study is characterized by theorical and bibliographical research on the subject. We consider eld a historic, social, cultural, political and psychological phenomenon which trespasses social and personal life paths, and must be understood in determined time, space, social class, gender and ethnicity relations, among other variables. The creation of specific policies to attend this segment doesn't take away the centrality of care and assistance that still remains on the family and community. The challenges are the strength of social participation, promotion of active aging and stimulation of intersectoral actions aiming the comprehensive care to the person who ages.
\end{abstract}

\section{Keywords}

Aging, social policies, elderly.

\section{Como você deve citar?}

ESCOBAR, Karin Alves do Amaral; SOUZA, Flávia Aparecida de. Análise de políticas sociais para idosos no brasil: um estudo bibliográfico. Cadernos UniFOA, Volta Redonda, n. 30, p. 47-55, abr. 2016. 


\section{INTRODUÇÃO}

O processo de envelhecimento social apresenta repercussões no campo social, econômico, biológico e comportamental.

De acordo com dados do Instituto Brasileiro de Geografia e Estatística (IBGE, 2010), o Brasil tem 20,6 milhões de idosos, representando assim 10,8\% da população total. As projeções indicam que, em 2060 , o país terá 58,4 milhões de pessoas idosas, o que representará $26,7 \%$ da população brasileira.

Dentre os fatores responsáveis por esse aumento da expectativa de vida, resultando na longevidade da população, está a queda na taxa de fecundidade, associada ao uso de métodos contraceptivos e à inserção da mulher no mercado de trabalho; os avanços tecnológicos, principalmente, no campo da saúde, a implementação de políticas sociais específicas para esse segmento, entre outros fatores (VERAS, 2003).

Essa realidade representa um grande desafio gerado pelas demandas sociais e econômicas, implicando na necessidade de adoção de políticas sociais específicas para melhorar as condições de vida dessa população.

As políticas sociais para o segmento idoso, no Brasil, são recentes e sofreram influências de organismos internacionais na sua elaboração e implementação, como a Organização Mundial da Saúde (OMS) e a Organização das Nações Unidas (ONU).

As décadas de 1980 e 1990 foram marcadas pela emersão do envelhecimento na agenda social como um problema social e político relevante. Esse período foi marcado por discussões em torno da criação de políticas sociais públicas para os idosos (LOBATO, 2012).

A publicização da velhice contribuiu para o surgimento de demandas específicas em torno de direitos e no interior da política. Essa nova emersão do envelhecimento à cena pública não se deve apenas ao seu crescimento numérico, mas aos processos de pressão, de reivindicações de instituições, profissionais da área, inclusive de organizações internacionais responsáveis pela problematização das questões relativas ao envelhecimento.

A primeira política que regulamenta direitos específicos para esse segmento foi resultado desses encontros e debates que foram realizados por meio de vários seminários que culminaram no documento intitulado "Políticas para a Terceira Idade nos anos 90", que originou mais tarde, em 1994, na Política Nacional do Idoso - Lei $n^{\circ} 8.842$, de 04 de janeiro de 1994. A partir dessa política, várias outras foram sendo instituídas, com destaque para o Estatuto do Idoso - Leis n ${ }^{\circ} 10.741$, de 03 de outubro de 2003.

Nesse sentido, questiona-se qual concepção de velhice é expressa nesses documentos?

Consideramos que a velhice é um fenômeno histórico, social, cultural, político, psicológico que perpassa as trajetórias de vida pessoal e social e que deve ser compreendida em determinados tempo, espaço, classe social, relações de gênero e de etnia, dentre outras variáveis.

Nesse sentido o presente artigo é resultado de um projeto de iniciação científica, voltado aos alunos de graduação que visa a incluí-los no ambiente de pesquisa e produção científica, realizado no âmbito do curso de serviço social do UniFOA. O estudo teve como objetivo realizar uma análise de políticas sociais e legislações, identificando a concepção de velhice expressa, os princípios, às orientações, os papéis previstos para a família, comunidade e Estado. 
O estudo em questão se caracteriza por pesquisa teórica e bibliográfica que objetiva desvendar conceitos, discussões polêmicas e teóricas. Esse tipo de pesquisa é de grande valia e eficácia ao pesquisador porque permite obter conhecimentos já catalogados em bibliotecas, editoras, internet.

Para Gil (2002, p .3), "a pesquisa bibliográfica é desenvolvida com base em material já elaborado, constituído principalmente de livros e artigos científicos".

A pesquisa bibliográfica abrange a leitura, análise e interpretação de livros, periódicos e documentos que se relacionem aos objetivos propostos pelo trabalho. Esse tipo de pesquisa é um procedimento metodológico importante na produção do conhecimento que possa originar, especialmente em temas pouco explorados, a postulação de hipóteses ou interpretações que servirão de ponto de partida para outras pesquisas (LIMA; MIOTO, 2007).

\section{DA VELHICE À TERCEIRA IDADE}

O século XX marcou a importância de se estudar o processo de envelhecimento, que já se manifestava no século anterior. Para Silva (2008), dois fatores se destacam como fundamentais e determinantes para o surgimento da velhice. 0 primeiro consiste na formação de novos saberes médicos que investiam sobre o corpo envelhecido, se consolidando com o campo da geriatria e gerontologia. 0 segundo fator se refere ao surgimento das aposentadorias, uma vez que, a partir de meados do século XIX, a velhice começou a ser objeto do discurso de legisladores sociais, contribuindo para a criação de instituições específicas, como as caixas de aposentadoria para a velhice e a criação de instituições para acolher a velhice menos favorecida.

Alguns idosos menos pobres eram mantidos pelas próprias famílias com algum auxílio do governo e outros considerados incapazes eram confinados em asilos, paróquia ou outras modalidades da administração pública que serviam ao mesmo tempo de hospitais, de asilo psiquiátrico, casas para velhos, etc. Durante muito tempo, o termo asilo associou-se à imagem de idosos pobres, da velhice carente, se configurando um elemento importante na construção da imagem da velhice.

Entretanto, a generalização das aposentadorias em idades cada vez mais reduzidas e o aumento da expectativa de vida nos países desenvolvidos, fez surgir um grupo cada vez maior de aposentados, contribuindo para a desconstrução da imagem da velhice associada à velhice doentia, marginalizada e dependente.

Outros fatores se destacam como fundamentais para o surgimento da categoria terceira idade: o discurso da gerontologia e a cultura do consumo. A gerontologia se mostrou engajada na criação de uma nova identidade para a velhice, passando a estimular a adoção de um novo estilo de vida da terceira idade, divulgando os benefícios que seriam decorrentes do engajamento dos sujeitos nesse 'novo modo de envelhecer' (SILVA, 2008). Desse modo, essa categoria foi criada para dar lugar a uma nova identidade da velhice, para justificar a crise da sociedade com o envelhecimento populacional, que é considerado como "fração improdutiva", sendo ressignificada como grandes consumidores, portanto, "de melhor idade". Os interesses da cultura do consumo e da indústria do envelhecimento também se constituíram como uma força importante por trás da emergência da noção de terceira idade. É nessa perspectiva que se insere o termo terceira idade, que extrapola os aspectos biológicos (FEATHERSTONE; HEPWORTH,1995, apud SILVA, 2008). 
Essa situação contribuiu para o surgimento do que convencionamos denominar de terceira idade, substituindo os termos de tratamento da velhice, o discurso da gerontologia social e os interesses da cultura do consumo (SILVA, 2008).

O termo Terceira Idade surge na França, no final dos anos de 1960, com o objetivo de expressar uma nova realidade de velhice, não mais associada a tempo de vida marcado pela miséria, doença e decadência, mas um tempo de atividades desligadas da vida profissional e família, um tempo específico de lazer, em que novos valores coletivos são elaborados (PEIXOTO, 1998).

A partir da década de 1970, a velhice começa a se tornar uma questão de maior visibilidade social, a partir do próprio discurso do campo da gerontologia e pelas mudanças no perfil demográfico com aumento do número de idosos.

\section{ENVELHECIMENTO POPULACIONAL E POLÍTICAS SOCIAIS}

A longevidade da população é um fenômeno da contemporaneidade, sendo o envelhecimento populacional, em termos demográficos, o processo de crescimento da população considerada idosa, ampliando a sua participação relativa no total da população (FREITAS, 2004).

O aumento no número de idosos no Brasil retrata a tendência de envelhecimento da população, conforme registra os dados do último censo do IBGE. Em 2010, esse número era de 23,5 milhões de pessoas com mais de 60 anos. 0 envelhecimento populacional sem dúvida deve ser considerado uma das maiores conquistas da humanidade, o que reflete a melhoria das condições de vida de uma população. 0 aumento dos idosos em todo o mundo deve-se às transformações socioeconômicas que determinaram grandes inovações científico-tecnológicas, associadas a melhores condições de vida.

As políticas públicas e os programas de atenção voltados para os idosos possuem papel importante na visibilidade adquirida por esse segmento, retirando o idoso do esquecimento e do silêncio e possibilitando a eles uma condição social mais justa. Para atender essa nova realidade e os desafios que a acompanham são necessários instrumentos legais que garantam proteção social e ampliação de direitos às pessoas idosas

Em âmbito internacional, destaca-se a realização, no ano de 1982, da I Assembleia Internacional do Envelhecimento, realizada em Viena.

No Brasil, é a partir da década de 1970 que esse processo vai adquirindo visibilidade. Em 1973, um estudo realizado pelo Ministério da Previdência observa o aumento da população idosa, apontando para a necessidade de criação de políticas sociais.

Em 1974, foram criadas leis, programas e projetos voltados para o envelhecimento tais como: Programa de Assistência ao Idoso - PAI, Projetos de Apoio à Pessoa Idosa (PAPI) (CABRAL, 2000).

Diante desse processo do aumento do número de idosos, durante a década de 1970, organizações privadas e públicas intensificam-se suas ações junto à população idosa. O Serviço Social do Comércio (SESC) adota programas para a terceira idade e a Legião Brasileira de Assistência passa a desenvolver programas para idosos de baixa renda (TEIXEIRA, 2008). 
No final da década de 1970, intensificam-se os movimentos em prol do idoso e de problematizações sobre o envelhecimento, como os eventos promovidos pela Sociedade Brasileira de Geriatria e Gerontologia que organizaram vários seminários para discussão do assunto (LOBATO, 2012).

As organizações não governamentais tiveram grande participação na defesa dos direitos dos idosos. 0 trabalho desenvolvido pelo SESC, pela Associação Nacional de Gerontologia (ANG), pela Sociedade Brasileira de Geriatria e Gerontologia (SBGG) com influência das agências internacionais como OMS e Organização das Nações Unidas (ONU) e Associação Internacional de Gerontologia (AIG) contribuíram no processo de visibilidade social do envelhecimento (TEIXEIRA, 2008).

Essas instituições contribuíram também para a produção de conhecimento gerontológico, formação de profissionais, intercâmbio com universidades internacionais, promovendo espaços de debate e seminários, sensibilizando a sociedade e o Estado em relação às questões do envelhecimento. Constituíram-se espaços de agregação de profissionais, de sujeitos ativos na problematização do envelhecimento e na sua ressignificação, lutando pela defesa do envelhecimento como um direito humano fundamental, contribuindo com os eventos realizados para aglutinar idosos, associações e organizações na direção da elaboração e implementação de políticas específicas para o segmento idoso.

Na década de 1980, foram realizados vários seminários regionais para discutir a questão do idoso com a participação de várias entidades interessadas na criação de políticas sociais para os idosos. Esse seminário gerou um documento intitulado "Políticas para a Terceira Idade nos anos 90", que originou, mais tarde, em 1994, a Política Nacional do Idoso - Lei 8.842, 1994 - (LOBATO, 2012).

Em 1999, a Assembleia Geral da ONU instituiu diretrizes para orientar o desenvolvimento de políticas sociais para os idosos, considerando que o envelhecimento da população não deve ser uma carga, mas sim uma oportunidade. Estabeleceu ainda princípios como Independência, Participação, Assistência, Autorrealização e Dignidade.

No ano de 2002, a ONU promoveu a II Assembleia Mundial do Envelhecimento, que originou o Plano Internacional de Madri, sinalizando a importância de um compromisso de todos os governantes para adotar ações, políticas e programas que garantam uma sociedade para todas as idades. Também no ano de 2002, a Organização Mundial de Saúde instituiu a Política para o Envelhecimento Ativo.

Entretanto, não podemos homogeneizar a compreensão das experiências do envelhecimento, desconsiderando aspectos como as diferenças de classes, gênero, etnia, entre outras, funcionando como uma ideologia da velhice.

A velhice, denominada terceira idade nos países desenvolvidos, é importada para a os países em desenvolvimento, como o caso do Brasil, marcado pela concentração de renda, desigualdades sociais e regionais, se configurando como um paradoxo.

\section{DIRETRIZES PARA O ENVELHECIMENTO}

Em âmbito internacional, destaca-se a realização de duas assembleias promovidas pela Organização das Nações Unidas, 1982 e 2002, que resultaram na elaboração de dois planos, Viena e Madri.

Esses Planos Internacionais sobre Envelhecimento, prevendo diretrizes e orientações, se constituíram marcos importantes para o estabelecimento de uma agenda internacional de políticas públicas para a população idosa. 
O Plano Internacional sobre Envelhecimento, de 1982, instituiu diretrizes para as políticas dirigidas aos idosos centradas na: promoção da independência e autonomia do idoso, reconhecendo-o como novo ator social, considerando suas necessidades e especificidades. O II Plano reconhecido como Plano de Ação Internacional sobre o Envelhecimento chamou a atenção para a necessidade da construção de uma sociedade inclusiva, para todas as idades. (CAMARANO; PASINATO, S/D)

Dentre os principais eixos destacam-se: idosos e desenvolvimento; promoção da saúde e bem-estar na velhice; ambiente propício e favorável para a vivência da velhice, com o objetivo de permitir que os idosos contribuam mais eficazmente para as suas comunidades e para o desenvolvimento de suas sociedades.

O envelhecimento populacional também foi pauta da Conferência Internacional sobre População e Desenvolvimento, realizada no Cairo, no ano de 1994, afirmando que o envelhecimento da população não deve ser visto como uma carga, senão como uma oportunidade. O Programa de Ação recomendou apoio, por parte dos governos e da sociedade civil, para reforçar a autoconfiança da população idosa e criar condições para o seu bem-estar, tornando-a capaz de trabalhar e viver independentemente em sua própria comunidade. Orientou ainda a importância de criação de um sistema de cuidados de longa duração, formal e informal, objetivando reforçar a capacidade das famílias de cuidar dos seus idosos dependentes e eliminar todas as formas de violência e preconceito com relação à população idosa, com atenção especial voltada para as mulheres.

A Assembleia geral da ONU, realizada em 1991, estabeleceu como princípios para o campo do envelhecimento: independência, participação, assistência, autorrealização e dignidade (CAMARANO; PASINATO S/D).

No que se refere à independência, entende-se o acesso à alimentação, moradia, apoio familiar e comunitário, oportunidade de trabalhar ou ter acesso a outras formas de geração de renda; acesso à educação e à programas de qualificação e requalificação profissisonal; viver em ambientes seguros adaptáveis à sua preferência pessoal.

Quanto à participação, consiste em permanecer integrado à sociedade, participar ativamente na formulação e implementação de políticas que afetem diretamente seu bem-estar e transmitir, aos mais jovens, conhecimentos e habilidades.

No eixo da assistência, situa-se a proteção da família e da comunidade, a garantia do acesso à assistência da saúde, prevenindo-se da incidência de doenças; acesso a serviços sociais e jurídicos que lhe assegurem melhores níveis de autonomia.

A autorrealização se refere à otimização das oportunidades para o desenvolvimento de suas potencialidades, acesso aos recursos educacionais, culturais, espirituais e de lazer da sociedade.

No eixo da dignidade, preconiza-se, essencialmente, a vivência dessa etapa da vida livre de maus-tratos.

Podemos observar que as diretrizes internacionais expressam uma concepção de velhice autônoma, independente, saudável, livre de violência e abandono. Entretanto, a realidade vivida pelos velhos do Brasil está longe desses preceitos.

No que se refere à questão das diretrizes para a área da saúde do idoso, a OMS elaborou uma política para o envelhecimento ativo, no ano de 2002 (BRASIL, 2005). 
O envelhecimento ativo é entendido como o processo de otimização das oportunidades de saúde, participação e segurança, com o objetivo de melhorar a qualidade de vida, à medida que as pessoas ficam mais velhas.

O termo envelhecimento ativo procura superar o termo envelhecimento saudável, reconhecendo que, além dos cuidados com a saúde, outros fatores afetam o modo como os indivíduos e as populações envelhecem. A abordagem do envelhecimento ativo se articula à concepção de reconhecimento dos direitos dos idosos, à igualdade de oportunidades e tratamento em todos os aspectos da vida, apoiando a responsabilidade dos idosos no exercício de sua participação nos processos políticos e em outros aspectos da vida em comunidade (BRASIL, 2005).

A política nacional de saúde da pessoa idosa apresenta como diretrizes a promoção do envelhecimento saudável, a manutenção da capacidade funcional, a assistência às necessidades de saúde do idoso, a reabilitação da capacidade funcional comprometida, a capacitação de recursos humanos especializados, o apoio ao desenvolvimento de cuidados informais e o apoio a estudos e pesquisas.

Essa política assume que o principal problema que pode afetar o idoso é a perda de sua capacidade funcional, compreendida como a perda das habilidades físicas e mentais necessárias para realização de atividades básicas e instrumentais da vida diária.

No Brasil, as políticas formuladas sofrem influência desse discurso internacional, como observado na Constituição Federal de 1988, Política Nacional do Idoso, Política Nacional de Saúde da Pessoa Idosa e Estatuto do Idoso.

Peixoto (1998) analisa a passagem do uso de 'velho' para 'idoso', tanto na França como no Brasil. 0 termo 'velho' estava fortemente associado aos sinais de decadência física e incapacidade produtiva, sendo utilizado para designar de modo pejorativo, sobretudo os velhos pobres.

A partir da década de 1960, o termo começa a desaparecer da redação dos documentos oficiais franceses, que passam a substituí-lo por 'idoso'.

Ao comentar o cenário brasileiro, Peixoto (1998) argumenta que a introdução da noção de terceira idade representa uma importação das denominações adotadas pelas políticas públicas francesas, sendo o termo 'velho' gradativamente substituído por 'idoso' nos documentos oficiais.

Em relação aos documentos nacionais, observamos que três forças sociais são acionadas para fazer frente às questões do envelhecimento: o Estado, com o papel de atuar como regulador, distribuindo incentivos e subsídios para que outras instâncias cumpram seu papel; a comunidade, viabilizando a participação desse segmento na sociedade; e a Família, como instância primeira, se responsabilizando por cuidados básicos com os idosos.

A Constituição Federal de 1988 traz, em seu artigo 230, que "a família, a sociedade e o Estado têm o dever de amparar as pessoas idosas, assegurando sua participação na comunidade, defendendo sua dignidade e bem-estar e garantindo-Ihes o direito à vida." (BRASIL, 1988).

Podemos observar essa orientação também no artigo $3^{\circ}$ do Estatuto do Idoso, que prevê que é obrigação da família, da comunidade, da sociedade, e do poder público assegurar ao idoso com absoluta prioridade, a efetivação do direito à vida, à saúde, à alimentação, à educação, à cultura, ao esporte, ao lazer, ao trabalho, à cidadania, à liberdade, à dignidade, ao respeito e à convivência familiar e comunitária. 


\section{CONSIDERAÇÕES FINAIS}

Essa emersão do envelhecimento à cena pública não se deve apenas ao seu crescimento numérico, mas aos processos de pressão, de reivindicações por organizações internacionais, responsáveis pela problematização das questões relativas ao tema.

Nesse contexto, eclodem propostas de melhoria de qualidade de vida, principalmente, via organizações privadas, antes mesmo das lutas por melhores condições objetivas de vida, especialmente para os mais pobres, que perdem a centralidade nas lutas e reivindicações dos movimentos em prol dos idosos.

Podemos perceber, no Brasil, a ampliação das associações não governamentais, lutando em prol dos direitos dos idosos e das ações do governo para os mais velhos, mas observamos que a responsabilidade dos cuidados aos idosos ainda é de responsabilidade da família e da comunidade.

Observamos que se constituem desafios o fortalecimento da participação social e promoção do envelhecimento ativo; a atenção integrada à saúde da pessoa idosa; o estímulo às ações intersetoriais, visando à integralidade da atenção.

Finalizamos com as reflexões de Debert, que sinaliza que a imagem do envelhecimento bem sucedido, associada à terceira idade, não oferece instrumentos capazes de enfrentar os problemas envolvidos na perda de habilidades cognitivas e de controles físicos e emocionais que estigmatizam o velho e que são fundamentais, na nossa sociedade, para que um indivíduo seja reconhecido como um ser autônomo, capaz de um exercício pleno dos direitos de cidadania (DEBERT, 1997).

\section{REFERÊNCIAS}

IBGE. Instituto Brasileiro de Geografia e Estatística. Censo 2010. Disponível em: <http://censo2010. ibge.gov.br/>. Acesso em: 29 Nov. 2015.

LIMA, T.C.S ; MIOTO, R.C.T. Procedimentos metodológicos na construção do conhecimento científico: a pesquisa bibliográfica. Rev. Katál. Florianópolis v. 10 n. esp., p. 37-45 2007. Disponível em: <http:// www.scielo.br/pdf/rk/v10nspe/a0410spe.pdf . Acesso em: 29 Nov. 2015.

BRASIL. Constituição da República Federativa, 1988.

Ministério da Justiça. Política Nacional do Idoso. Lei 8.842, 1994.

Ministério da Justiça. Política de Saúde da Pessoa Idosa, portaria no 2.528 de 19 de outubro de 2006.

Ministério da Justiça. Estatuto do Idoso, Lei 10.741, 2003.

Ministério da Saúde. Envelhecimento ativo: uma política de saúde. Brasília, 2005. Disponível em: <http://bvsms.saude.gov.br/bvs/publicacoes/envelhecimento_ativo.pdf>. Acesso em: 29 Nov. 2015.

CABRAL, M. S. As políticas brasileiras de seguridade social: previdência social. Capacitação de políticas sociais. Brasília: CEFESS/ ABEPSS/CEAD/NED/ UnB, 2000. 
CAMARANO, A. A; PASINATO. 0 envelhecimento populacional na agenda das políticas públicas. Disponível em: $<$ http://www.en.ipea.gov.br/agencia/images/stories/PDFs/livros/Arq_16_Cap_08.pdf>Acesso em: 29 Nov. 2015.

DEBERT, G.G. Envelhecimento e curso da vida. Disponível em: <https://periodicos.ufsc.br/index.php/ ref/article/viewFile/12564/11720>. Acesso em: 29 Nov. 2015

FREITAS, E. V. Demografia e epidemiologia do envelhecimento. PY, L. et al. (orgs). Tempo de Envelhecer. percursos e dimensões psicossociais. Rio de Janeiro. NAU Editora, 2004.

GIL, A. C. Métodos e Técnicas de Pesquisa Social. 6. ed. São Paulo: Atlas. 2002.

LOBATO, A. T. G. Serviço Social e Envelhecimento: perspectivas de trabalho do Assistente Social na área da saúde. BRAVO, M. I. S; VASCONCELLOS, A. M. (Orgs.). Saúde e serviço social. 5. ed. Rio de Janeiro: UERJ. 2012.

ONU. Organização das Nações Unidas. Plano de Ação Internacional sobre o envelhecimento, 2002. Brasília, Secretaria Especial de Direitos Humanos, 2007.

PEIXOTO, C. Entre o estigma e a compaixão e os termos classificatórios: velho, velhote, idosos, terceira idade. BARROS, M. M. L. (Org.). Velhice ou terceira idade? Rio de Janeiro: FGV. 1998.

SILVA, L. R. Da velhice à terceira idade: o percurso histórico das identidades atreladas ao processo de envelhecimento. História, Ciências, Saúde - Manguinhos, Rio de Janeiro. v. 15, n. 1, p. 155-168, jan./ mar. 2008. Disponível em: <http://www.scielo.br/pdf/hcsm/v15n1/09.pdf>. Acesso em: 29 Nov. 2015.

VERAS, R. "A longevidade da população: desafios e conquistas". Revista Serviço Social e Sociedade, n. 75, São Paulo: Cortez. 2003.

TEIXEIRA, S. M. Envelhecimento e Trabalho no tempo do capital: implicações para a proteção social no Brasil. São Paulo: Cortez, 2008. 